This is a self-archived version of an original article. This version may differ from the original in pagination and typographic details.

Author(s): Pitkänen, Silja

Title: Lapset USSR in Construction ja N.S. Frauen-Warte -lehtien valokuvissa 1930-1939

Year: 2021

Version: Published version

Copyright: (C 2021 Venäjän ja Itä-Euroopan tutkimuksen seura

Rights: In Copyright

Rights url: http://rightsstatements.org/page/lnC/1.0/?language=en

Please cite the original version:

Pitkänen, S. (2021). Lapset USSR in Construction ja N.S. Frauen-Warte -lehtien valokuvissa 1930-1939. Idäntutkimus, 28(2), 55-60. https://doi.org/10.33345/idantutkimus.110182 


\section{Lapset USSR in Construction ja N.S. Frauen-Warte -lehtien valokuvissa 1930-1939}

Silja Pitkänen

Kubinkan pikkukaupungissa, noin 60 kilometrin päässä Moskovasta, sijaitsee isänmaallinen teemapuisto nimeltä Park Patriot. Puistoon kuuluvat 1970-luvulla perustettu Kubinkan panssarimuseo sekä Kubinkan lentotukikohdan yhteydessä toimiva ilmailumuseo. Lähivuosina aluetta on laajennettu, ja vuonna 2016 avattiin koko perheelle suunnattu sotilaallinen teemapuisto. Puistossa lapset voivat esimerkiksi harjoitella ampumista sekä kokeilla, millaista on osallistua sotilaskoulutukseen. Länsimaiset mediat ovat nimittäneet teemapuistoa "militaristiseksi Disneylandiksi".

Keväällä 2020 puisto oli jälleen otsikoissa, sillä alueelle rakennettiin Venäjän asevoimille ja natsi-Saksan voittamiselle omistettu suuri katedraali. Kirkon sisätiloihin koottiin mosaiikkiteoksia, joissa esiteltiin monenlaisia aiheita, muun muassa Krimin niemimaan liittämistä Venäjään. Myös Stalin ja Putin esiintyivät mosaiikeissa. Teokset nostattivat kiivaan keskustelun, ja lopulta Stalin ja Putin poistettiin. Mosaiikeista käyty debatti on osoitus visuaalisten symbolien voimasta, visuaalisen ja poliittisen yhteenkietoutumisesta, sekä - teemapuiston ollessa koko perheen vierailukohde - myös lapsille suunnatusta visuaalisesta propagandasta.

Visuaalinen propaganda oli voimissaan myös 1930-luvulla, niin Neuvostoliitossa kuin Saksassakin. Valokuvasta ja varsinkin valokuvaa hyödyntävistä kuvalehdistä tuli keskeinen vaikuttamisen keino maailmansotien välillä. Nuori neuvostovaltio pyrki hankkimaan kansainvälisiä liittolaisia, ja yksi keinoista oli valokuvajournalismiin nojaava visuaalinen propaganda. Neuvostoliiton graafisten taiteiden kustantamo julkaisi suurikokoista kuvalehteä, nimeltään SSSR na Stroike. Lehdelle työskentelivät monet Neuvostoliiton eturivin taiteilijat ja journalistit, muun muassa taiteilijapariskunta Aleksandr Rodtšenko ja Varvara Stepanova sekä toimittaja Mihail Koltsov. Lehti ilmestyi Neuvostoliiton lisäksi englanniksi, saksaksi, 
ranskaksi ja espanjaksi käännettynä. Lehden englanninkielinen nimi oli USSR in Construction. Olen käyttänyt tutkimuksessani pääosin lehden englanninkielistä versiota.

USSR in Constructionissa julkaistiin runsaasti suurikokoisia valokuvia. Lehdelle kuvanneet ammattilaiset saivat erilaisia toimeksiantoja sen mukaan, mille teemalle kulloinenkin numero oli "omistettu". USSR in Constructionissa esiteltiin valokuvien kautta esimerkiksi Neuvostoliiton teollisuusalueita ja -laitoksia, esikaupunkirakentamista sekä neuvostoliittolaisten perheiden jokapäiväistä elämää. Moni lehden numero oli omistettu neuvostotasavalloille. Varsin usein - jopa yllättävän usein - lehdessä julkaistiin valokuvia lapsista.

Samaan aikaan Saksassa kansallissosialistinen naisliitto NS-Frauenschaft julkaisi erityisesti naisille suunnattua aikakauslehteä N.S. Frauen-Warte. Lehden sivuilla oli muun muassa ruokareseptejä ja ompelukaavoja. Niiden ohella julkaistiin myös reportaaseja ajankohtaisista aiheista puolueen näkökulmaa painottaen. Naisille suunnatussa lehdessä ilmestyi myös runsaasti lapsiin ja kasvatukseen liittyviä artikkeleja, ja lapset esiintyivät usein myös ajankohtaisia ja poliittisia aiheita käsittelevien artikkeleiden kuvituksessa. N.S. Frauen-Warte edusti natsipuolueen ideologiaa koko olemassaolonsa ajan, vuodesta 1932 vuoteen 1945.

Sekä SSSR na Stroikessa että N.S. Frauen-Wartessa hyödynnettiin valokuvajournalismia poliittisten tavoitteiden esittelemiseksi ja edistämiseksi. Niiden vertailun kautta käy ilmi, millä tavoin lapsikuvastoa käytettiin 1930-luvun propagandassa Neuvostoliitossa ja natsi-Saksassa, ja millä tavoin propagandakuvastot olivat erilaisia tai yhdenmukaisia.

Lapsia esitettiin molemmissa lehdissä luonnollisesti kuvissa, joiden aiheena oli perhe ja jokapäiväinen elämä. Kuvissa lapset esimerkiksi ruokailivat yhdessä vanhempiensa

Kuva 1. Kansallissosialistisen naisliitto NS-Frauenschaftin johtaja Gertrud Scholtz-Klink lapsineen. N.S. Frauen-Warte, syyskuu 1935, s. 203. Kuva: Hanni Umlauf.

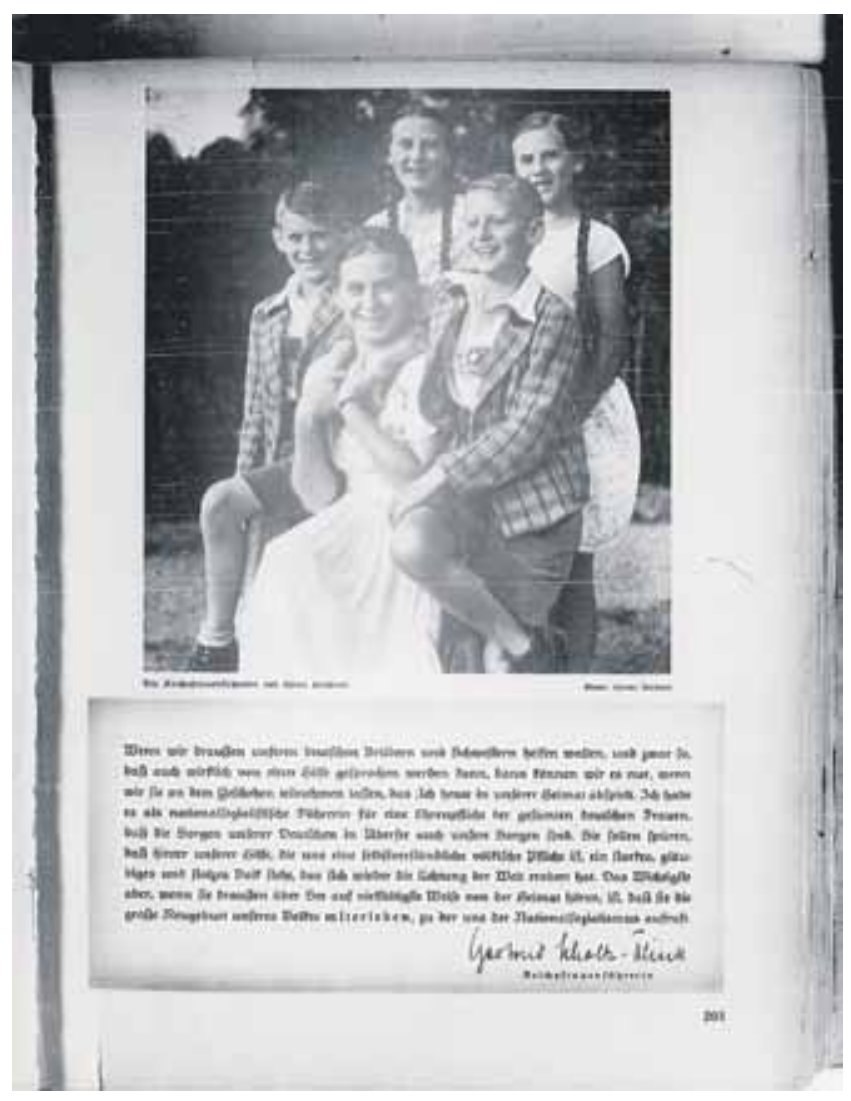


kanssa kotona, tai perheet viettivät aikaa piknik-retkillä. Erityisesti neuvostoliittolaisissa propagandavalokuvissa lapset myös söivät ylellisiä herkkuja, kuten jäätelöä ja makeisia, ja kuvateksteissä kerrottiin, että nämä herkut olivat Neuvostoliitossa osa jokapäiväistä elämää. Niin Neuvostoliitossa kuin Saksassakin lapset esiintyivät myös valokuvissa, joiden aiheena olivat lastentarhat, päiväkodit, synnytyssairaalat, sekä valtioiden lapsille ja nuorille tarjoamat vapaa-ajan harrastukset, kuten poliittiset nuorisojärjestöt aktiviteetteineen. Kaikki lasten ja nuorten instituutiot ja harrastusmahdollisuudet politisoitiin USSR in Construction ja N.S. Frauen-Warte -lehdissä. Kummassakin lehdessä myös korostettiin maiden korkeita syntyvyyslukuja sekä kannustettiin lasten hankkimiseen ja monilapsisuuteen.

Lastentarhojen ja koulujen kontekstissa lapset esitettiin kuvissa yhtenäisenä ja yhdenmukaisena ryhmänä, kuin mallina tulevaisuuden yhtenäiselle kansakunnalle. Neuvostoliittolaisessa lehdessä esiteltiin kouluja useammin kuin saksalaisessa lehdessä - N.S. Frauen-Wartessa koulut eivät olleet aiheena yhtä usein, mahdollisesti siitä syystä, että Kolmannessa valtakunnassa koulut natsifioitiin nopeasti, ja lapset olivat monesti kansallissosialistisempia kuin heidän vanhempansa. Näin ollen koulut ja niissä annettu poliittinen kasvatus aiheuttivat toisinaan erimielisyyksiä ja kiistoja perheissä.

Sekä neuvostoliittolaisessa että saksalaisessa lehdessä lapset olivat lisäksi usein suurissa ryhmissä, esimerkiksi marssimassa leveillä kaduilla ja suurilla stadioneilla. Lehdissä olikin runsaasti myös kuvastoa, joka yhdisti sotilaalliset aiheet, vallankäytön ja lapset.

USSR in Construction -lehdessä pieniä pioneereja kuvattiin muun muassa vierailemassa puna-armeijan sotilaiden luona. Saksalaiset lapset taas esitettiin esimerkiksi heiluttamassa

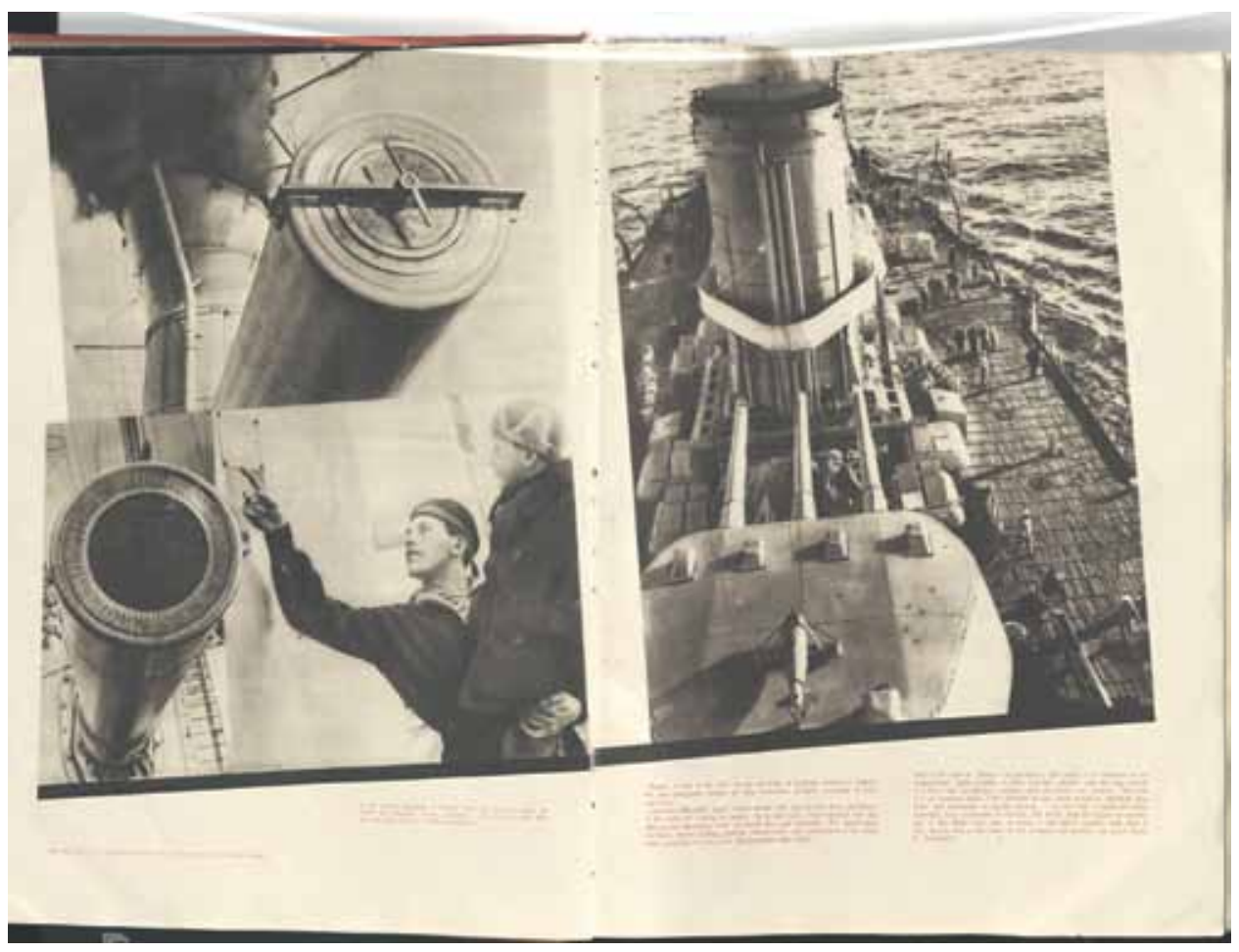

Kuva 2. Pioneeripoika vierailemassa sota-aluksella. USSR in Construction 2/1933 "Is devoted to the 15th Anniversary of the Red Army", ss. 24-25. Numeron takasivulla luetellut valokuvaajat: P. Lass, N. Petrov, L. Poljakov, M. Han, A. Šaihet ja N. Štertser. 
natsilippuja. USSR in Constructionissa esiteltiin myös neuvostotasavaltojen elämää lasten kautta. Neuvostoliittolainen elämä ja arki tuotiin ilmi hyvin samankaltaisena kaikkialla Neuvostoliitossa, ja neuvostotasavaltojen kohdalla korostettiin myös "paikallisväriä", esimerkiksi luonnonvarojen suhteen. N.S. Frauen-Wartessa puolestaan Kolmannen valtakunnan aluelaajennuksia motivoitiin ja perusteltiin toisinaan lasten kuvien avulla, esimerkiksi visualisoimalla "nälkää näkevien" itävaltalaisten lasten "pelastamista" Saksaan. Myöhemmin lehdessä kerrottiin, että kun Itävalta liitettiin Kolmanteen valtakuntaan, Saksaan pelastetut itävaltalaiset lapset saattoivat jälleen palata turvallisesti koteihinsa. Lisäksi N.S. FrauenWartessa muisteltiin Saksan keisarikunnan siirtomaata, Saksan Lounais-Afrikkaa, ja esiteltiin alueella toimivaa saksalaista koulua ja alueella asuvaa, natsilippua heiluttavaa saksalaista tyttöä. Myös Neuvostoliiton ja Saksan poliittiset johtajat, varsinkin Stalin ja Hitler, esiintyivät usein kuvissa lasten kanssa. Politiikka, valta ja lapsiaiheet kietoutuivat lehtien kuvituksessa yhteen monin tavoin.

Lapsi on voimakas kuvallinen symboli. Kuvat lapsista vaikuttavat katsojien tunteisiin, ja lapsissa kulminoituvat unelmat paremmasta tulevaisuudesta. Tämä on hyvin inhimillistä. Lasten kuvien - staattisten tai liikkuvien - kautta on myös mahdollista myydä lähes mitä tahansa pesuaineista aina äärimmäisiin poliittisiin ideologioihin ja sodankäyntiin asti. Sodat esitetään ja propagoidaan usein siten, että niissä ei ole kysymys tappamisesta ja kuolemisesta, aluelaajennuksista tai rajojen puolustamisesta, vaan naisten ja lasten suojelemisesta ja paremman

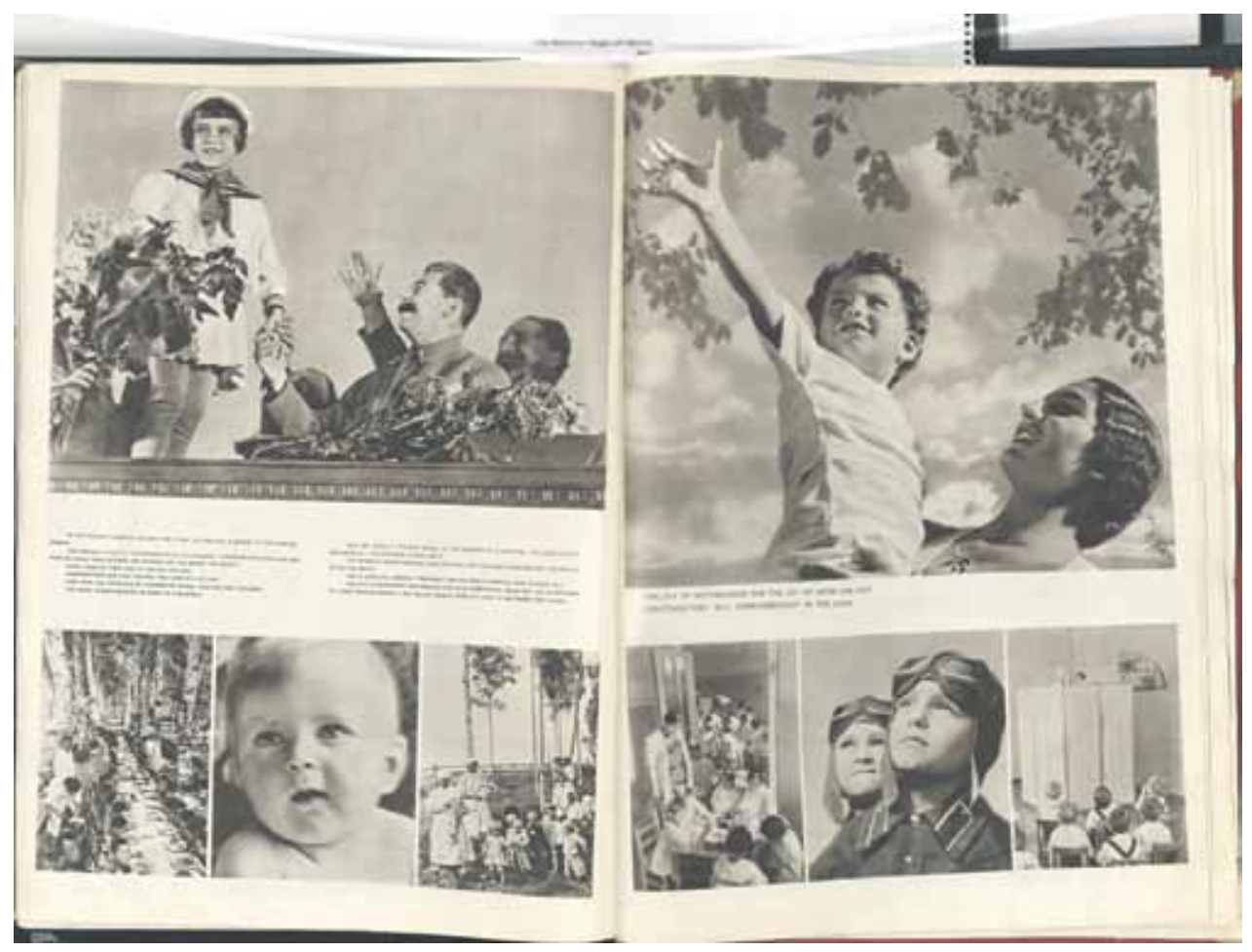

Kuva 3. Stalin pitelee merimiesasuisen tytön kättä. USSR in Construction 9-10-11-12/1937, "The Stalin Constitution", ss. 108-109. Kuvaajaluettelossa mainitaan mm.: M. Alpert, S. Alperin, J. Berliner, G. Gratšev ja A. Gostev. 
tulevaisuuden turvaamisesta heille, olipa kyseessä sitten hyökkäävä tai puolustava osapuoli.

Olemmeko oppineet mitään 1930-luvusta, jolloin lapsiaiheisella propagandakuvastolla esiteltiin neuvostoliittolaisen ja saksalaisen arjen erinomaisuutta, ja hyödynnettiin kuvastoa, joka oli usein myös varsin militaristista, jopa sotaa lietsovaa? Osittain olemme, osittain emme. Saksassa ei useinkaan enää näe mediassa kuvia saksalaisista lapsista militaristisissa yhteyksissä. Venäjällä puolestaan on Kubinkan teemapuiston lisäksi runsaasti lasten ja nuorten vapaa-ajan aktiviteetteja, jotka liittyvät tavalla tai toisella isänmaallisuuteen ja sodankäyntiin. Yksi esimerkki visuaalisuuden saralla ovat "Venäjä - minun historiani" (Rossija - moja istorija) -historiapuistot eri puolilla Venäjää. Ne käyttävät uusimpia digitaalisia menetelmiä ja tehosteita esitellessään Venäjän historiaa lapsia ja nuoria kiinnostavalla tavalla. Hanke kertoo Venäjän historiasta isänmaallisin painotuksin, ja esimerkiksi Pietarissa museo sijaitsee Natsi-Saksan kukistamisen muistoksi perustetun Voiton puiston (Park Pobedi) vieressä. Näissä historiapuistoissa sotilaallista voimaa propagoidaan yhä lapsille.

Tekeekö toisen maailmansodan synkkä historia sekä sen tarkoituksellinen esiintuominen, erityisesti Venäjällä, johtopäätöksistäni ylikorostuneen synkeitä? Iltojen pimennyttyä olen työhuoneeni ikkunasta ulos katsellessani kiinnittänyt huomiota uuteen villitykseen, lasten "lasersotaan", jota leikitään laseraseilla. Ehkäpä niin kutsutussa lännessä me emme myöskään ole täysin vapaita sodan ja aseiden ihannoinnista? Ehkä emme kyseenalaista kovin voimakkaasti ajatusta, että sotaa käymällä voisi saavuttaa paremman tulevaisuuden? Lasten lasersota tuskin useinkaan on erityisen isänmaallista, vaan muistuttaa ennemminkin hippaleikkiä, mutta sodan leikkimiseen joka tapauksessa sisältyy, vähintäänkin implisiittisesti, militaristisia arvoja, asenteita ja olettamuksia, niin Saksassa, Venäjällä kuin Suomessakin. 1930-luvun Neuvostoliitossa ja Saksassa sotaisat leikit ja niiden visualisaatiot olivat poliittisia ja valtion kannustamia, kun taas tänä päivänä lasten sotaleikit, mukaan lukien virtuaaliset sotapelit, ovat enemmänkin kaupallisesti motivoituneita, jännittäviä viihdemuotoja. Aikuisten "sotaleikit" taas ovat vaarallisia tässä ja nyt. Samoin kuin aikaisempia sotia on oikeutettu naisten ja lasten suojelemisella, Yhdysvalloissa ja Euroopassa suosiota saavuttaneen äärioikeistolaisen QAnon-liikkeen pohjimmaisena ajatuksena on pelastaa lapset pahaksi uskotun eliitin oletetulta kaltoin kohtelulta. Lapset ovat siis edelleen voimakas propagandistinen, väkivaltaan ja jopa sotaan kannustava symboli.

Lasten, propagandan ja sodan paradoksaalinen yhdistelmä on kiinnostanut minua pitkään sekä herättänyt monia kysymyksiä, ja jotkut niistä ovat jalostuneet tutkimuskysymyksiksi. Väitöskirjani on pyrkimys löytää näihin kysymyksiin vastauksia lapsia esittävien propagandavalokuvien osalta vuosikymmeneltä, jolloin monet kriisit kärjistyivät toiseksi maailmansodaksi. Toivoakseni tutkimusmatkani on kiinnostava, ehkä jopa valaiseva, minun lisäkseni myös tutkimukseni lukijoille.

FM Silja Pitkäsen yleisen historian alaan kuuluva väitöskirja "The Future Belongs to Us!'” Children in Soviet and German Propaganda Photographs Published in USSR in Construction and N.S. Frauen-Warte 1930-1939 tarkastettiin 13.11.2020 Jyväskylän yliopiston humanistis-yhteiskuntatieteellisessä tiedekunnassa. Vastaväittäjänä toimi dosentti Annette Vowinckel (Humboldt-Universität zu Berlin) ja kustoksena dosentti, yliopistotutkija Simo Mikkonen (Jyväskylän yliopisto). 


\section{Lähteet}

Mikkonen, Erkka (2020), Sotilaiden katedraali vahvistaa Kremlin ja kirkon liittoa. - Yle 26.6.2020. $<$ https://yle.fi/uutiset/3-11419414>

Walker, Shaun (2015), Vladimir Putin opens Russian 'military Disneyland' Patriot Park - The Guardian, 16 Jun 2015. <https://www.theguardian.com/world/2015/jun/16/vladimir-putin-opens-russianmilitary-disneyland-patriot-park $>$ 